\title{
Entre hospitalidade e hostilidade: famílias em situação de imigração na rede pública de educação brasileira
}

\author{
Between hospitality and hostility families in immigration situation in the \\ brazilian public education network
}

\author{
Leila de Carvalho Mendes \\ Doutora em Língua Portuguesa \\ Professora Adjunta da Universidade do Estado do Rio de Janeiro - RJ - Brasil. \\ lcmendess@gmail.com
}

\begin{abstract}
Kelly Russo Doutora em Educação Professora Adjunta da Faculdade de Educação da Baixada Fluminense e do Programa de Pós-graduação em Educação, Comunicação e Cultura ambos da Universidade do Estado do Rio de Janeiro Co-coordenadora do Grupo de Estudos sobre Educação, Interculturalidade e Linguagens.- RJ - Brasil. kellyrussobr@gmail.com
\end{abstract}

\author{
Kellen Dias de Barros \\ Doutora em Literatura Comparada \\ Professora Adjunta da Universidade do Estado do Rio de Janeiro - RJ - Brasil. \\ kellendiasb@yahoo.com.br
}

\begin{abstract}
Resumo: Este artigo apresenta uma reflexão sobre as leis voltadas para imigração e refúgio a partir de uma pesquisa mais ampla realizada numa escola pública da Baixada Fluminense. Partindo de entrevistas com educadoras, famílias e de oficinas pedagógicas realizadas com crianças em situação de imigração/refúgio, seguimos uma perspectiva crítica de educação intercultural e a concepção histórico-cultural para desenvolver reflexões. O recorte trazido para este artigo destaca a dicotomia observada entre o aparato hospitaleiro das leis brasileiras de acolhimento ao refugiado e o cotidiano hostil enfrentado pelas famílias para matricular filhos na escola. Considerando esse objetivo, organizamos o artigo em três sessões: apresentamos os sujeitos da pesquisa e a base teórico-metodológica de nossas análises; tecemos reflexões sobre as leis brasileiras que os acolhem; por fim, tecemos algumas conclusões provisórias, sobre a situação dessas famílias e a responsabilidade do Estado brasileiro em garantir a dignidade humana destas, como das demais famílias que vivem no Brasil.
\end{abstract}

Palavras-chave: Políticas educacionais. Refúgio. Migração. Educação básica.

Abstract: This article presents a reflection on the laws focused on immigration and refuge based on a broader research carried out in a public school in the Baixada Fluminense (greater Rio de Janeiro area). Starting with interviews with educators, observing the immigrant children's class routine and teaching workshops, we followed a critical perspective of intercultural education and the historical-cultural conception to develop reflections. The outline brought to this article highlights the dichotomy observed between the hospitable apparatus of Brazilian refugee reception laws and the hostile daily life faced by families to enroll their children at school. Considering this objective, we organized the article in three sections: first, we present the research subjects and the theoretical-methodological basis of our analyzes; second, we reflect on the Brazilian laws that welcome them; finally, we make some provisional conclusions about the situation of these families and the responsibility of the Brazilian State to guarantee their human dignity, as well as that of other families living in Brazil.

Keywords: Educational policies. Refuge. Migration. Basic education. 
Entre hospitalidade e hostilidade: famílias em situação de imigração na rede pública de educação brasileira

Desde a década de 1980 o Brasil passou a ser considerado como um país receptor de novos fluxos migratórios, principalmente na última década, no fenômeno conhecido como "migrações sul-sul”" (BAENINGER et al., 2018). As razões para essa mudança de status do país são diversas, uma dentre elas é o perfil das leis brasileiras em relação à imigração e refúgio, visto como um dos mais avançados no mundo em termos de possibilidades de acolhimento. Mas ao chegar no novo país, com qual realidade o sujeito em situação de refúgio e sua família se defrontam? Especialmente em relação a inserção de seus filhos na escola, que lutas precisam travar para matriculá-los?

O interesse das autoras sobre imigração e refúgio surge após uma demanda à FEBF (Faculdade de Educação da Baixada Fluminense, da UERJ) feita por profissionais da saúde e da educação do município de Duque de Caxias, solicitando apoio para melhor se relacionarem com as famílias congolesas em situação de imigração/refúgio, que chegavam aos serviços da rede pública em 2016. A partir daí, iniciamos uma pesquisa ampla ${ }^{2}$, em uma escola pública municipal da baixada fluminense que recebe o maior número de crianças imigrantes, e esse artigo traz um recorte, um olhar sobre um aspecto que nos tocou. Se por um lado as leis são hospitaleiras, por outro lado as dificuldades para fazer valer essas leis não são poucas.

Como veremos no texto, historicamente o Brasil oferece a hospitalidade das leis de acolhimento e a hostilidade de uma sociedade profundamente desigual. Acreditamos que seja fundamental afirmarmos a importância de defender a legislação já existente e reforçar a responsabilidade de toda a sociedade, inclusive de professores e professoras, no compromisso de defesa desses direitos no contexto da escola pública.

1 “Mitos e pecados de uma indisciplina científica": a base teórico-metodológica da pesquisa

O que me dá prazer é percorrer como um equilibrista essa linha de fronteira entre pensamento e sensibilidade, entre inteligência e intuição, entre poesia e saber científico

A epígrafe acima traduz muito de nossos pensamentos e foi retirada do discurso "Mitos e pecados de uma indisciplina científica", proferido por Mia Couto (2011) para um Ciclo de Conferências sobre Biologia na Noite ${ }^{3}$ realizado na Universidade de Aveiro, em 2006. O escritor reflete sobre o desejo de ter feito um discurso mais formal, mas ele diz preferir a conversa, afirmando que é o diálogo que o alimenta, a intersecção entre os dois saberes. Assim como o 
autor/poeta, percorremos essa linha tênue, como equilibristas que ora tendem para um lado, ora para o outro.

Desde 2018, temos realizado um estudo de caso em uma escola pública de um município periférico do estado do Rio de Janeiro. Nessa escola municipal, foram aplicadas três diferentes estratégias de coleta de dados, todas de acordo com os procedimentos éticos estabelecidos pelo Conselho de Ensino e Pesquisa da Universidade do Estado do Rio de janeiro: entrevistas com profissionais da educação (professores/as, representantes da coordenação escolar e da gestão pública) diretamente envolvidos/as no tema do estudo, oficinas pedagógicas realizadas com crianças brasileiras e em situação de imigração e/ou refúgio matriculadas nesta escola e entrevista coletiva, contando com a participação dos responsáveis pelas crianças que participaram das oficinas.

Durante o desenvolvimento do estudo, muitas de nossas reflexões têm sido tecidas na relação com diferentes colaboradores/as, em especial as contribuições de uma mulher congolesa em situação de refúgio, que vive desde 2014 no estado do Rio de Janeiro, e que foi bolsista ao longo de todo o segundo ano do projeto ${ }^{4}$.

Como linha condutora do nosso trabalho, adotamos a perspectiva crítica de educação intercultural, para refletir sobre práticas sociais e educacionais relacionadas ao reconhecimento de diferenças e ao desenvolvimento desta perspectiva na educação (CANDAU, 2000), e também as contribuições da concepção histórico-cultural (VYGOTSKY, 2007), que fornece referencial teórico para se pensar práticas mais inclusivas.

A partir desses referenciais, construímos então algumas reflexões sobre o lugar que a pessoa estrangeira ocupa e a tensão entre hospitalidade e hostilidade existente nos processos de integração de crianças e de suas famílias na sociedade brasileira. Vale lembrar que compreendemos integração como um processo multidimensional (social, econômico, linguístico e cultural) e bidirecional que envolve os esforços por parte da pessoa em situação de imigração, que procura se integrar na sociedade de acolhimento, assim como a responsabilização do Estado e a abertura desta sociedade na relação com essas pessoas estrangeiras (RACHÉDI et LEGAULT, 2008).

2 Hospitalidade nas leis: a proteção à pessoa em situação de imigração e/ou de refúgio no Brasil

O que faz, andar a estrada? E' o sonho. Enquanto a gente sonhar, a estrada permanecerá viva. Épara isso que servem os caminhos, para nos fazerem parentes do futuro.

Mia Couto, Terra Sonâmbula 
A epígrafe retirada do livro Terra Sonâmbula, do escritor moçambicano Mia Couto, nos leva a pensar sobre o que faz uma pessoa e sua família a deixar sua terra, a deixar tudo para trás. Ela parece acreditar na existência de um lugar melhor. Um lugar em que ela poderá recomeçar e ser feliz. E a ponte entre esse lugar que já não faz parte da vida dessas pessoas e o futuro, é a estrada. É a estrada que vai permitir que ela sonhe. Ela é a ponte entre aquilo que ela precisa deixar e o novo destino. Além disso, ao pensarmos nos que saem, muitas vezes tendo enfrentado conflitos que ameaçaram suas vidas, percebemos que chegam no Brasil cheios de esperança de uma vida melhor, uma vez que deixaram para trás os motivos de tanto sofrimento e depositando nas leis do novo país a crença de um futuro mais digno.

De acordo com Lima (2017), o governo brasileiro tem por tradição conceder refúgio. Em 1950, o governo Getúlio Vargas adota uma política específica, e assina a Convenção de Genebra de 1951, sobre o status dos refugiados.

Em 1988, a Constituição Federal não faz distinção entre brasileiros e estrangeiros, garantindo a todos os mesmos direitos, dentre eles, o direito à educação, assim como "o direito à vida, à liberdade, à igualdade, à segurança e à propriedade" (Artigos $5^{\circ}$ e $6^{\circ}$, nos direitos sociais). Essa premissa também pode ser lida no Estatuto da Criança e do Adolescente, em parágrafo único, do art. $3^{\circ}$," que esclarece que:

\footnotetext{
Os direitos enunciados nesta Lei aplicam-se a todas as crianças e adolescentes, sem discriminação de nascimento, situação familiar, idade, sexo, raça, etnia ou cor, religião ou crença, deficiência, condição pessoal de desenvolvimento e aprendizagem, condição econômica, ambiente social, região e local de moradia ou outra condição que diferencie as pessoas, as famílias ou a comunidade em que vivem. (BRASIL, 1990).
}

O documento também afirma, no artigo $4^{\circ}$, que é dever da família e da comunidade, da sociedade em geral e do poder público, efetivar os direitos referentes à vida, à saúde, à alimentação, ao esporte, à profissionalização, ao respeito, à liberdade e a convivência familiar e comunitária. No artigo $53^{\circ}$ o documento deixa claro que "A criança e o adolescente têm direito à educação, visando ao pleno desenvolvimento de sua pessoa, preparo para o exercício da cidadania e qualificação para o trabalho" (Idem), incluindo, dentre outros, o direito a ter acesso à escola pública e gratuita. Podemos verificar que o ECA (Estatuto da Criança e do Adolescente) corrobora os direitos assegurados na Constituição, garantindo a todas as crianças o direito à educação.

A Lei de Diretrizes e Bases da Educação Nacional 9394/96, no artigo 2º também ratifica a Constituição Federal acerca do dever da família e do Estado sobre a educação. O art. $5^{\circ}$ deixa claro que: 
O acesso ao ensino fundamental é direito público subjetivo, podendo qualquer cidadão, grupo de cidadãos, associação comunitária, organização sindical, entidade de classe ou outra legalmente constituída, e, ainda, o Ministério Público, acionar o Poder Público para exigi-lo. (BRASIL, 1996).

Em 1997, o Brasil iniciou uma política nacional voltada para a situação de pessoas em situação de refúgio com o Estatuto dos Refugiados (9474/97). Essa Lei define os mecanismos para a implementação da Convenção de Genebra de 1951 e, está em conformidade com a Declaração de Cartagena (1984), que define refugiado como o indivíduo que "devido a fundados temores de perseguição por motivos de raça, religião, nacionalidade, grupo social ou opiniões políticas encontre-se fora de seu país de nacionalidade e não possa ou não queira acolher-se à proteção de tal país”. (BRASIL, 1997)

Lima (2017) lembra ainda que, desde então, diversos acordos foram assinados pelo governo brasileiro com o Escritório do Alto Comissariado das Nações Unidas para os Refugiados (ACNUR), em conformidade com o Relatório sobre a Cooperação Brasileira para o Desenvolvimento Internacional 2011-2013 (LIMA, 2017). A Lei Brasileira de Refugiados estabeleceu o Comitê Nacional de Refugiados (Conare) em 1997, sob os auspícios do Ministério da Justiça e Cidadania (MJ), como um órgão deliberativo coletivo com os poderes necessários para política nacional de refugiados, de acordo com os valores estabelecidos na Constituição Federal.

Essa lei, nos artigos $43^{\circ}$ e $44^{\circ}$ esclarece e determina que frente a condição atípica dos refugiados, a matrícula na instituição de ensino pública/privada deve ser facilitada e efetuada apenas mediante o documento de solicitação de refúgio. Também pela Lei da Migração (13445/2017), as crianças estrangeiras têm direito ao acesso à educação da mesma forma que as brasileiras. No art. $3^{\circ}$, que cita os princípios que regem a política migratória brasileira, no inciso XI, podemos ler "acesso igualitário e livre do imigrante a serviços, programas e benefícios sociais, bens públicos, educação, assistência jurídica integral pública, trabalho, moradia, serviço bancário e seguridade social [...]”. (BRASIL, 2017)

Esses documentos aparentam assegurar alguma hospitalidade, compreendendo esta como amparo legal à pessoa em situação de refúgio, garantindo direitos e não apenas gestos de ajuda humanitária/filantrópica. No entanto, em nossa pesquisa, a pessoa que possui o status de refúgio parece contar mais com a ajuda de pessoas ou grupos da sociedade civil, como podemos verificar no depoimento de uma das mulheres congolesas, entrevistada em nossa pesquisa:

Quando eu cheguei no aeroporto, não sabia o que fazer... Ela [uma moça desconhecida] ficava me olhando de longe e eu olhando pros lados sem saber o que fazer. Ela chegou e me perguntou: você acabou de chegar? Vai pra onde? Eu disse olha, sinceramente eu não sei, porque ela chegou falando a minha língua, 
então foi mais fácil. Eu expliquei pra ela. Ela disse: "eu cheguei na mesma situação que você, mas eu posso te ajudar". (...) Foi ela quem me levou pra Caritas, pra Policia Federal, me mostrou pra Igreja, ela que me explicou como funcionava tudo aqui. (JS, comunicação pessoal, 2019)

Em relação à escola pública, através dos relatos das famílias e dos profissionais da educação, vemos como muitas vezes as instituições que por lei deveriam garantir os direitos dessas populações, não parecem estar preparadas para esse acolhimento. No decorrer da pesquisa pudemos perceber a dificuldade das pessoas em situação de imigração/refúgio para conseguirem efetivar a matrícula de seus filhos nas escolas públicas portando apenas o documento emitido pela Policia Federal, de solicitação de refúgio, como é garantido por lei. Situação que vai ser solucionada a partir do desejo pessoal, do empenho de alguns profissionais mais sensíveis ao tema, em lugar de ações governamentais voltadas para a divulgação e a garantia da efetivação das leis existentes:

$\mathrm{Na}$ época, eu escrevi um e-mail para ele [secretário de educação] pedindo que ele fosse sensível na matrícula porque... primeiro tinha a barreira da língua. As pessoas estavam num lugar estranho e é difícil para o brasileiro conseguir vaga, imagina pra... Eu não tenho certeza se ele leu esse e-mail. Esse e-mail existiu, eu passei para ele, mas não tive a resposta [...] aí eu procurei a subsecretaria, na época a subsecretaria de ensino[...] o que elas fizeram? Elas mandaram para gente, nosso grupo da igreja, a resolução de matrícula. (Docente 9, comunicação pessoal, 2018).

Como analisa Almeida (2001, p.165), a partir da promulgação da Lei brasileira de Refúgio, Lei 9747/1997, o Brasil tem sido visto como o país com uma das leis "mais avançadas e generosas do continente americano" em relação à temática, o que tem provocado um aumento exponencial no número de solicitações de refúgio no país (Almeida, 2001, p.380). Segundo dados da CONARE (2016), apesar de não ter um número de solicitações de refúgios tão expressivo como em países da União Europeia, EUA ou Canadá, o Brasil tem cerca de 10 mil pessoas reconhecidas pelo Estado brasileiro como refugiados, e recebe em média, quatro mil solicitações anualmente.

Desse modo, enquanto nossa legislação acolhe e ampara o estrangeiro, garantindo-lhes os mesmos direitos dos cidadãos brasileiros, na prática, o dia a dia das pessoas em situação de imigração/refúgio no Brasil não é nada hospitaleiro, especialmente no caso das famílias que chegam em uma região que parece pouco acostumada a acolher estrangeiros, conforme indica o depoimento de uma mulher congolesa, moradora da Baixada Fluminense:

Tem gente que você não conhece, mas que percebe que você não é daqui e quer perguntar tudo sobre a sua vida, aí, eu não consigo... "Ah, você não é daqui?", "Você é de onde?”, " Sou africana", "De qual parte?”, "Sou do Congo...", “Onde fica o Congo? Lá tem muita guerra? Você veio aqui de avião ou veio daqueles caminhos que a gente vê na TV? Foi por causa da guerra ou você veio porque quis?” Eu nem conheço a pessoa, então, é muito difícil... Fica 
muito difícil pra mim... Então às vezes eu respondo: foi porque eu quis, só pra não ter que falar mais nada. (JS, comunicação pessoal, 2019).

A falta de conhecimento e de informação sobre as especificidades e da legislação que protege pessoas em situação de imigração e/ou refugio, parece dificultar muito as trajetórias dessas famílias. E a busca pela garantia ao direito à educação de seus filhos, ou de moradia, muitas vezes parece ser uma verdadeira odisseia de estrangeiros em terras estranhas...

3 Hospitalidade e hostilidade: a experiência de estar em situação de imigração/refúgio na rede pública de educação

Há que se aventurar, deixar o conforto dos lares, erguer a espada e seguir viagem por um grande sonho. Realizando ou não, não importa tanto... "A vida é breve, a alma é vasta" (Mensagem, Pessoa)

Iniciamos essa sessão trazendo a ideia do estrangeiro, daquele que há de se aventurar. $\mathrm{O}$ estrangeiro seria aquele que vem de outra terra, para além das fronteiras de seu país, fronteira tomada a princípio como demarcação territorial, definida por relações de força entre os homens, pela história e pela língua. No entanto, se por um lado, para o capital, não existem mais fronteiras, por outro, a acumulação do capital produz fronteiras muitas vezes intransponíveis. Dessa forma, para os que têm meios não há fronteiras e para aqueles que não têm, resta, senão o confinamento em seus territórios explorados e devastados, a fuga.

A epígrafe nos fala daquele que, ao deixar a terra natal, deixa um pouco de si, de sua história e do conforto do seu lar, porém, ergue a sua espada e vai para realizar seu sonho. Daí em diante, só importa a viagem. No momento em que atravessa a fronteira, passa a ser um estrangeiro, que precisará mais do que nunca se adaptar para sobreviver, pois a dinâmica dos grupos é sempre que o outro, o estrangeiro, se adapte ao modo de se vestir, de falar, de se comportar.

Para Bauman (2017) o estranho, por ser "diferente", costuma causar ansiedade e medo por ser difícil prever seu comportamento, ao contrário das pessoas com as quais interagimos diariamente e que acreditamos saber o que esperar. Esses estranhos estão sempre, de uma forma ou de outra, presentes em nossas vidas. Morrison pergunta ao leitor o que esperamos que os estrangeiros façam. "Perturbar. Trair. Provar que não são como nós? Por isso é tão difícil saber o que fazer com eles.” (MORRISON, 2019, p.61) e adverte, citando a célebre frase da peça de JeanPaul Sartre, Entre quatro paredes, "O inferno são os outros", sobre a falsidade do inferno. Morrison (idem) afirma ainda que não existem estrangeiros, mas versões de nós mesmos. Algumas dessas versões nós abraçamos e outras não, e que desejamos, na maioria das vezes, nos proteger. 
Mas quem são os estranhos com os quais convivemos? Os loucos, os deficientes, os que vivem à margem e os estrangeiros que, com o aumento do fluxo migratório, na condição de imigrantes e/ou refugiados, estão cada vez mais presentes entre nós, desafiando-nos a conviver com eles.

Esse medo é explicitado por um docente entrevistado por nós, ao comentar sobre como percebe o sentimento dos pais das crianças brasileiras em relação às crianças estrangeiras.

Os pais das crianças brasileiras falavam que eles [os estrangeiros] eram diferentes, que eles eram estranhos, que eles tinham medo e eles passavam isso para as crianças. Acho que a comunidade ainda os vê como os diferentes, né? É o olhar sobre a roupa, porque a roupa deles é muito colorida. Eles olham como diferente... E eles têm medo, principalmente em relação... Isso eu ouvi e me chocou: "Eles vêm de lá pra pegar o trabalho de quem tá aqui, se já tá ruim!", imagina... (Docente 1, comunicação pessoal, 2018).

Quando se fala [de estrangeiro] negro da África parece que o peso é maior... Saber que ele veio da África e é um refugiado, parece que é um marginal para as famílias brasileiras. (Docente 10, comunicação pessoal, 2019).

Segundo Bauman (2017), Kant insiste, no texto “Terceiro artigo para a paz perpétua”, sobre a importância de se afirmar o direito das pessoas e famílias em situação de imigração. O autor reforça essa ideia ao insistir que: "não é uma questão de filantropia, mas de direito que tem um estrangeiro de não ser tratado de forma hostil pelo fato de estar em território alheio" (KANT apud BAUMAN, 2017, p.73). O que Kant reivindica, segundo Bauman, é a hospitalidade, o amparo legal para que essas pessoas possam recomeçar a vida com dignidade. Mas nos perguntamos, serão as leis suficientes? E ao mesmo tempo nós respondemos: não, não são suficientes, no entanto, elas oferecem o respaldo jurídico necessário para que possamos sair em defesa dos direitos propostos nas leis.

Nesse sentido, entre tantas outras necessidades, estrangeiros precisam de meios que façam valer essas leis hospitaleiras, pois não basta a determinação fria de documentos para implementar uma real política de acolhimento dos refugiados. Dentre tantos complicadores, um deles é a invisibilidade do tema, conforme relato de uma professora entrevistada, que "nem imaginava que havia refugiado em Duque de Caxias quando eu vim pra secretaria em 2015” (Comunicação pessoal, docente 10, 2018). E, no momento em que se aproxima dessa realidade, ela se diz surpreendida pelas demandas e pelos obstáculos impingidos pela situação:

Era muito difícil essa comunicação, porque na grande maioria, os pais não falavam português. Então, a nossa comunicação era com as crianças. [...] Então, eles chegavam e era uma confusão e eles falavam alto e muitas vezes choravam, não conseguiam se comunicar. [...] $\mathrm{Na}$ questão da pobreza que a gente percebe em muitas famílias, principalmente entre os refugiados, a situação é muito mais extrema. Então, você fala "volta tal dia, de repente..." e 
chegava na escola e não tinha vaga [...]. E a gente sabe das dificuldades de se pagar uma passagem, de se locomover, de não ter o contato telefônico e muitas vezes eles têm medo dessa comunicação. (Docente 10, comunicação pessoal, 2018)

Além das dificuldades linguísticas, a falta de institucionalidade de procedimentos para o acolhimento dessas famílias foi outro obstáculo enfrentado. Segundo as professoras entrevistadas, o atendimento para essa população acontecia por "iniciativas particulares dentro de diferentes setores" da rede municipal (Docente 10, comunicação pessoal, 2018), conforme depoimentos abaixo:

Não foi a secretaria que orientou as escolas, foram as escolas que encontraram as suas formas de desenvolver seus desafios da língua, da cultura, da acolhida, então aí a gente fica com a parte da articulação da escola com a própria experiência. (Docente 9, comunicação pessoal, 2018)

E se não existem orientações para os gestores acerca da matrícula dos alunos, também não há orientações pedagógicas para os professores, que se deparam com estudantes que não falam português e não contam com suporte material e pedagógico para dar conta desse desafio.

Desse modo, o que a princípio pareceria se constituir em um terreno hospitaleiro, termina por se constituir em um ambiente hostil no qual, para se cumprir a letra da lei, termina por necessitar da sensibilidade/caridade de outros. O direito que se transforma na caridade: a boa vontade de uma diretora que se sensibilize com o drama das famílias e aceite fazer a matrícula do aluno mesmo sem ter vaga; do professor que tenta, da forma que pode, estabelecer comunicação com a crianças que não falam a língua portuguesa.

Um outro aspecto que é determinante, e já desenvolvido em artigo anterior ${ }^{5}$, segundo as/os professores/as das crianças imigrantes/refugiadas angolanas ou congolesas são vítimas de preconceito. Mesmo em uma sociedade onde a maior parte da população poderia ser vista como negra e pobre, o pensamento colonial se estabelece, ressaltando e hierarquizando diferenças:

Sim, eles sofrem [racismo]primeiro por serem estrangeiros (...). Por mais que a escola tenha a maioria dela formada por crianças negras existe preconceito. Eles olham para o outro que tem a pele mais escura que a deles. Eles acham que é pra mexer ou chamar o outro disso ou daquilo e tal. Eu ouvi relatos de mães que disseram que eles descobriram o que era racismo aqui na escola porque de onde eles vieram todos eram negros. Aqui eles descobriram o significado dessa palavra racismo. (Docente 3, comunicação pessoal, 2018)

Para Castles (2002, p.47), a migração contemporânea constitui-se em um processo social com dinâmicas mais complexas e difíceis que em décadas anteriores, e a globalização e a intensificação do movimento migratório têm provocado a diversidade desses fluxos. No caso das migrações sul-sul, parece-nos produtivo adotar a perspectiva da "colonialidade", para identificar a permanência de estruturas hierárquicas racistas/sexistas coloniais e eurocêntricas nos processos 
transnacionais de incorporação de migrantes em sociedades metropolitanas. Concordamos com Grosfoguel, Oso e Christou (2014) ao afirmarem que a maior compreensão do fenômeno da migração requer a distinção entre as diversas experiências de migração e de discriminação que os diferentes grupos humanos vivenciam nas metrópoles, determinadas não somente pelo fato de serem estrangeiros, mas também devido ao país específico de origem, à raça, ao gênero, ao perfil sexual ou a outras categorias que tornam o desafio da integração ainda mais complexo.

No caso das famílias congolesas em Duque de Caxias, a partir das falas das professoras entrevistadas, podemos verificar que, mesmo em uma sociedade onde a maior parte da população poderia ser vista como negra e pobre, o pensamento colonial se estabelece, ressaltando e hierarquizando diferenças:

Aqui nós temos muito alunos negros, mas o aluno do Congo é diferente. O tom da pele é mais escuro, o penteado deles, eles se destacam com os penteados... Então a gente olha e vê que não é uma criança brasileira. (Docente 3, comunicação pessoal, 2018)

Entretanto, apesar dessas professoras identificarem a experiência de discriminação vivenciada por essas crianças e suas famílias dentro e fora da escola, percebemos nas falas da maior parte dessas profissionais, uma tendência a minimizar a importância dessas situações de preconceito ou de discriminação vivenciadas pelas crianças:

O preconceito está tão dentro da gente que não dá pra separar só porque eles vieram de outro lugar e dizer que é por causa disso. Eu acho que não, porque já ocorre preconceito, não acontece porque eles vieram... Acontece porque acontece. É estranho falar dessa forma, mas é porque a gente tem preconceito de tanta coisa, tanta coisa que se a gente for colocar em uma lista... Haja papel! (...) E preconceito acontece comigo, com outra pessoa na rua, às vezes uma coisa aqui e outra ali... É difícil vencer o preconceito, e eles não estão livres disso, infelizmente. (Docente 6, comunicação pessoal, 2018).

É necessário destacar que a Constituição Federal de 1988, no art. $5^{\circ}$, prescreve o racismo como crime inafiançável e que qualquer minimização dos atos de racismo corrobora com a manutenção de um contexto em que sujeitos sofrem agressões e retirada de direitos unicamente pela cor de sua pele. Dessa forma, mais uma vez, estamos frente à dualidade hospitalidade/hostilidade. O racismo sofrido por essas crianças precisa ser enfrentado com políticas públicas de formação de professores que promovam reflexão e orientem os professores sobre o tema. 


\section{Reflexões finais}

Conforme referência na parte introdutória desse estudo, esse artigo representa um esforço de reflexão e análise de dados iniciais de uma pesquisa mais ampla, ainda em andamento, um estudo de caso, realizado em uma escola pública situada em um município periférico do estado do Rio de Janeiro, e, apesar dos limites da amostra, consideramos importante tecer algumas reflexões finais, ainda que provisórias sobre um aspecto que nos tocou: a hospitalidade das leis brasileiras e o cotidiano hostil encontrado pelos imigrantes/refugiados na rede pública de educação.

Nessa trajetória, Mia Couto nos inspirou a refletir sobre o que é imigrar, pensando para além da racionalidade científica e explicitar o diálogo constante travado, em nosso grupo, entre pensamento e sensibilidade, inteligência e intuição, poesia e saber científico. Dualidades sempre presentes em nossas discussões. Por isso, o artigo mostra que apesar de o Brasil ter entrado na rota das migrações internacionais a partir da década de 80 , quando o perfil das leis brasileiras toma caminhos hospitaleiros, as narrativas dos docentes entrevistados revelam que o caminho percorrido pelas famílias estrangeiras para matricular seus filhos na escola não tem sido fácil. Os obstáculos vão desde do desconhecimento dos direitos desses cidadãos garantidos nas leis que os protegem, quanto aos fenômenos do xenofobismo e do racismo.

Os relatos dos docentes trazem o desconhecimento e o despreparo da rede pública de educação para fazer valer a lei e garantir os direitos constitucionais dos imigrantes/refugiados.

Por estes motivos, em um momento em que o país recebe cada vez mais imigrantes, é de fundamental importância a criação de políticas que divulguem, esclareçam e orientem as secretarias de educação acerca dos direitos assegurados a essas pessoas e sobre os procedimentos que devem ser seguidos para assegurar o acolhimento das crianças estrangeiras e suas famílias nas escolas.

Também é importante pensar na criação de políticas voltadas à formação de professores, de forma a preparar os docentes e profissionais que trabalham nas escolas a lidarem com essas crianças e famílias, a partir de práticas pedagógicas que respeitem a cultura do outro e promovam sua inclusão. Nesse sentido, é preciso reconhecer que o fenômeno do racismo e da xenofobia caminham lado a lado com o tema da imigração e que os mesmos precisam ser compreendidos com toda sua complexidade e multidimensionalidade, de forma que as práticas pedagógicas possam ser efetivamente inclusivas.

Por último, a título de conclusão, uma vez que as leis brasileiras asseguram aos estrangeiros os mesmos direitos que os cidadãos brasileiros, resta-nos investir na realização de ações que efetivamente assegurem aos imigrantes/refugiados o que está prescrito na lei. 


\section{Dialogia}

MENDES, Leila de Carvalho; RUSSO, Kelly; BARROS, Kellen Dias de. Entre hospitalidade e hostilidade: famílias em situação de imigração na rede pública de educação brasileira

\section{Referências}

ACNUR, Ministério da Justiça, 2010. Disponível em: https://www.acnur.org/portugues/wpcontent/uploads/2018/02/Ref\%C3\%BAgio-no-Brasil A-prote $\%$ C3\%A7\%C3\%A3o-brasileiraaos-refugiados-e-seu-impacto-nas-Am\%C3\%A9ricas-2010.pdf

ALMEIDA, Guilherme Assis de. A Lei 9.474/97 e a definição ampliada de refugiado: breves considerações. In ARAUJO, Nádia de; ALMEIDA, Guilherme Assis de (coord.). O Direito Internacional dos Refugiados: uma perspectiva brasileira. Rio de Janeiro: Renovar, 2001.

BAENINGER, R. et al. Migrações sul-sul. Campinas, SP: Núcleo de Estudos de População Elza Berquó-NEPO/UNICAMP, 2018.

BAUMAN, Z. Estranhos à nossa porta, 2017. Rio de Janeiro: Zahar, 2017.

BRASIL. Constituição da República Federativa do Brasil. Brasilia: Senado Federal, 1988 Disponível em:

https://www2.senado.leg.br/bdsf/bitstream/handle/id/508200/CF88_EC85.pdf?sequence=1. Acessado em 26/09/2019.

BRASIL. Estatuto da Criança e do Adolescente Lei no 8.069, de 13 de julho de 1990. Disponível em: http://www.planalto.gov.br/ccivil 03/leis/18069.htm; Acessado em 26/09/2019.

BRASIL. Lei de Diretrizes e Bases da Educação Nacional. Lei n 9.394, de 20 de dezembro de 1996. Brasília: Senado Federal, 1996. Disponível em:

https://www2.senado.leg.br/bdsf/bitstream/handle/id/70320/65.pdf. Acessado em 26/09/2019.

BRASIL. Lei de Migração. Lei no 13.445, de 24 de maio de 2017. Disponível em: http://www.planalto.gov.br/ccivil 03/ Ato2015-2018/2017/Lei/L13445.htm. Acessado em 26/09/2019.

BRASIL. Estatuto dos Refugiados. Lei no 9.474, de 22 de julho de 1997. Disponível em: http://www.planalto.gov.br/ccivil 03/leis/19474.htm. Acessado em 26/09/2019.

CASTLES, Stephen. Environmental change and forced migration: making sense of the debate. New issues in refugee research, Working Paper No. 70, 2002. Disponível em: http://www.imi.ox.ac.uk/pdfs/environmental- change-and-forced-migration. Acessado em $01 / 10 / 2014$.

CASTLES, Stephen. Cotidiano escolar e cultura(s): encontros e desencontros. In: CANDAU, Vera Maria (org.). Reinventar a Escola. Petrópolis: Vozes, 2000.

COUTO, Mia. Terra Sonambula. São Paulo: Companhia das letras, 2015.

COUTO, Mia. Se Obama fosse africano. São Paulo: Companhia das Letras, 2011.

JUBILUT, Liliana Lyra. Melhorando a integração dos refugiados: novas iniciativas no

Brasil. In: Revista Forced Migration, edição 35, julho de 2010. 


\section{Dialogia}

MENDES, Leila de Carvalho; RUSSO, Kelly; BARROS, Kellen Dias de. Entre hospitalidade e hostilidade: famílias em situação de imigração na rede pública de educação brasileira

LIMA, João Brígido Bezerra et al. Refúgio no Brasil: caracterização dos perfis sociodemográficos dos refugiados (1998-2014). Brasília: Ipea, 2017. Disponível em: http://repositorio.ipea.gov.br/bitstream/11058/8061/1/Ref\%C3\%BAgio\%20no\%20Brasil cara cteriza $\% \mathrm{C} 3 \% \mathrm{~A} 7 \% \mathrm{C} 3 \% \mathrm{~A} 3 \mathrm{o} \% 20 \mathrm{dos}^{2} \% 20$ perfis $\% 20$ sociodemogr $\% \mathrm{C} 3 \% \mathrm{~A} 1$ ficos $\% 20 \mathrm{dos}^{2} \% 20$ refugi ados 1998-2014.pdf.

MORRISON, T. A origem dos outros: seis ensaios sobre racismo e literatura. São Paulo: Companhia das Letras, 2019.

LÉGAULT, Gisèle; RACHÉDI, Lilyane. L'intervention interculturelle. Montréal: Gaëtan Morin Éditeur, 2008.

PESSOA, F. Mensagem. Porto Alegre: L\&PM, 2006.

RUSSO, K. Imigrantes, refugiados e indígenas: interculturalidade, bilinguismo e o direito à educação. Projeto PROCIENCIA, UERJ, 2017.

RUSSO, K.; MENDES, L. Crianças imigrantes/refugiadas em Duque de Caxias: subsídios para professores/as sobre interculturalidade, plurilinguismo e o direito à educação. Projeto de Iniciação à Docência, CETREINA, UERJ, 2018 - 2019.

RUSSO, Kelly; MENDES, Leila; BORRI-ANADON, Corina. Crianças em situação de imigração na escola pública: percepções de docentes. Cadernos de Pesquisa, São Paulo, v. 50, n. 175, p. 218, jan./mar. 2020. https://doi.org/10.1590/198053146943.

SOUZA, Fabrício Toledo de. O caso Battisti e o caso dos refugiados congoleses: a justiça em termos de luta. In: Lugar Comum, n. 30, 2012, p. 85-94. Disponível em:.

http://uninomade.net/wp-

content/files $\mathrm{mf} / 110510120512 \mathrm{O} \% 20 \mathrm{caso}^{2} \mathrm{20}$ Battist $\% 20 \mathrm{e} \% 20 \mathrm{os} \% 20$ refugiados $\% 20$ congoleses $\% 20-\% 20 \mathrm{Fabr}^{2} \% \mathrm{C} 3 \%$ ADcio $\% 20$ Toledo $\% 20 \mathrm{de} \% 20$ Souza.pdf. Acessado em: 15 de setembro de 2014.

VYGOTSKY. L.S. Formação social da mente. Martins Fontes. São Paulo, 2007.

Recebido em: 31 mar. 2020/ Aprovado em: 06 jul. 2020

Cite como

(ABNT NBR 6023:2018)

MENDES, Leila de Carvalho; RUSSO, Kelly; BARROS, Kellen Dias de. Entre hospitalidade e hostilidade: famílias em situação de imigração na rede pública de educação brasileira. Dialogia, São Paulo, n. 35, p. 200-213, maio/ago. 2020. Disponível em:

https://doi.org/10.5585/dialogia.n35.16913.

American Psychological Association (APA) 
Mendes, L. de C., Russo, K., \& Barros, K. D. de. (2020, maio/ago.). Entre hospitalidade e hostilidade: famílias em situação de imigração na rede pública de educação brasileira. Dialogia, São Paulo, 35, p. 200-213. https://doi.org/10.5585/dialogia.n35.16913.

\footnotetext{
${ }^{1}$ As migrações Sul-Sul entre e em direção aos países da América Latina, na última década, demonstram como os esforços para bloquear os refugiados e requerentes de asilo nos Estados Unidos e na Europa só fizeram a crise migratória global mais complexa. Baeninger e Logus (2018) organizaram uma coletânea que discute a situação do Brasil e de demais países latino-americanos nesse contexto, e o Escritório das Nações Unidas sobre Drogas e Crime (UNODC) para a América Central e Caribe, publicou, em 2016, relatório que mostra como as redes de tráfico humano estão levando à América migrantes da África e do Oriente Médio que entram no continente pelo Cone Sul da América, passando por cidades como Rio de Janeiro e São Paulo.

${ }^{2}$ Projeto de pesquisa: "A integração de crianças em situação de refúgio na escola pública de Duque de Caxias" (RUSSO, 2017); (RUSSO; MENDES, 2018).

${ }^{3}$ Estudo que tem como "tecto duplo a noite e a biologia (Couto, M. 2011)"

${ }^{4}$ Bolsa de nível médio oferecida pelo Programa de Apoio Técnico às Atividades de Ensino, Pesquisa e Extensão (PROATEC), ao longo do período de janeiro a dezembro de 2019.

${ }^{5}$ RUSSO, Kelly; MENDES, Leila; BORRI-ANADON, Corina. Crianças em situação de imigração na escola pública: percepções de docentes. Cadernos de Pesquisa, São Paulo, v. 50, n. 175, p. 256-272, jan./mar. 2020. https://doi.org/10.1590/198053146943.
} 